\title{
Mini-review Summary
}

\author{
Ronald Osei Mensah ${ }^{1, *} \&$ Charles Obeel ${ }^{2}$ \\ ${ }^{1}$ Department of Sociology and Anthropology, University of Cape Coast, Cape Coast, Ghana \\ ${ }^{2}$ Languages Department, Accra Academy, Ghana \\ *Corresponding author: Department of Sociology and Anthropology, University of Cape \\ Coast, Cape Coast, Ghana. E-mail: ronald.mensah@stu.ucc.edu.gh
}

Received: August 26, 2020 Accepted: October 20, 2020 Published: November 19, 2020

doi:10.5296/jsr.v12i1.17957ＵRL: https://doi.org/10.5296/jsr.v12i1.17957

\begin{abstract}
This mini review brings to bear a situation that occurred in the rural areas of West Africa where the inhabitants accused others of being responsible for the loss of their genitals. The town of reference is Zorse, which is inhabited by the Kusasi tribe in the North Eastern part of Ghana. Anthropologists and psychologists explain anxiety assault as a fear reaction that emanates from a people's belief that a person can cause sex organs to vanish or shrink. Charles Mather used ethnography to describe detailed accounts of happenings. This current paper provides a systematic review of happenings based on the information gathered from the script of Mather. It is revealed that the explanations offered are also grounded in bioengineering and psychology.
\end{abstract} Keywords: West Africa, socio psychological, genital, pathology, disappearance, cultural belief 


\section{Introduction}

Some nineteen years back, in the southwestern part of Nigeria, irate mob killed 12 people within two weeks, whom they accused of stealing people's genitals (Dan-Ali, 2001). These occurrences in Ilesa were not novel nor akin to Nigeria alone. News reports gather popular opinions that consider the disappearance of genitals as a crime committed by those who have mystic powers or medicines that make sex organs disappear or even cause permanent impotence.

Similar to the West African phenomenon of genital theft is the koro of Southeast Asia. Individuals with the koro effect experience anxiety disorder with the fear that their genitals are shrinking and that they might die as a result of that (Bartholomew 2000: 91-125; Chowdhury 1996; Edwards 1984). One typical example is the work Hallowell (1941) did with the Salteaux. Someone remarked that the term 'koro' embodies the beliefs held by a given society, especially, Asians, that make them fear other individuals. With the case of person to person, the phenomenon entails feeling anxious that a person's sexual organ would shrink. When it comes to the group level, it manifests itself as an epidemic, collective hysteria, mass psychogenic illness among others when it comes to the issue of penis snatching. Another reason for attributing to koro and other related occurrences as pathological, stems from the fact that these happenings are transitory. Bartholomew $(1994,2000)$ recommends as a substitute to the medical model, that we must understand koro to mean a group delusion disorder; something embedded in a sub - culture.

\subsection{Objective of the Paper}

This paper seeks to bring to bear the roles and beliefs associated with genital theft that occurred among the people of Zorse in Northeastern Ghana.

\subsection{Significance of the Study}

The importance of this paper in unearthing the realities associated with genital theft among the people of Zorse in the Northeastern Ghana cannot be overemphasized. The paper gives a brief summary of Charles Mather accusations of genital theft which would be invaluable to any individual or researchers who want to have a first-hand knowledge of issues relating to genital theft in Northern Ghana; the enigma and realities attached to the case. Lastly, this paper would represent a knowledge base to which any individual who is researching into this area or any related area may refer.

\subsection{Theoretical Orientation}

Irrespective of the theories behind genital theft, intellectuals agree that to fully understand issues of a sub - culture, those phenomena must be considered culturally and assessed on local terms.

\section{Method}

When it comes to issues of genital theft, no one is ready to give a firsthand account or to say it 
happened to me or I experienced it. This presents a challenge to assessing the meaning in the cultural setting. The incidences reported can also not be supported anthropologically.

\subsection{Background of the Kusasi}

The Kusasi people can be found in the Upper East Region of the Republic of Ghana. The land covers $8842 \mathrm{~km}^{2}$. It is bordered to the north by Burkina Faso, and to the East by Togo. The Kusasi people originally lived in between the Red Volta and the Ghana - Togo ranges. It is believed that the town got its name from the hills upon which it was founded, because Zorse (also spelt as Zawse) means hill in Kusaal, which is the language of the Kusasi people.

\section{Authors' Position on Genital Theft}

The indigenous meaning ascribed to genital theft has to do with a people's perception in relation to mystical causes of their problems. The basic unit of the Kusasi society; social and spatial is the yir (compound). The members on the yir are referred to as yirdiim (household people) and they are kinsmen (paternally related by blood), their wives and their children.

The division points on the compound are geared toward future partitioning of descendants. The Kusasi practice exogamy, therefore it is possible for the husband and wife to belong to different clans. Bringing others into the yir or compound is accepted as part of the marriage rites and these 'outsiders' may duel in that place for a very long time (See Awedoba 1989a, 1989b, 1990). Lastly, opposed to the main system of inheritance which is patrilineal, is witchcraft which is considered to be maternally inherited or gotten from outside of the yir or its lineage.

The case that happened in Zorse, a community in North - Eastern Ghana, is similar to the cases of genital theft that the press usually reports. It was however, shocking that the individual involved; Atanga whose plight was not different from the aforementioned factors, was not lynched even though he was considered an outsider because he was not living in Zorse. Atanga was spared due to his social relations.

\subsection{Findings}

News reportage sums up a popular opinion portraying genital theft as a criminal act and that some people are considered sorcerers and believed to possess spiritual powers or black magic to commit these crimes by making people's genitals vanish. Genital theft therefore is a representation of the outward insecurity and fear that people entertain about unseen phenomena in West Africa. The knowledge and acceptance of the supernatural are intertwined with personal and collective identity of the people. Finally, as against the status quo, witchcraft can only be inherited through the mothers' bloodline and not within the yir or compound and its lineage.

\subsection{Sociological Implications of Genital Theft}

The belief in the existence of the supernatural has the tendency of affecting the psychological make-up of individuals and groups. This is because most deeds are attributed to deities, evil spirits and other supernatural forces though they are not physically seen. Therefore, 
occurrences such as acts of God or human errors; omissions and commissions are not subjected to scientific nor empirical evidence. The effect is that innocent people may be accused of wrong doing if they do not find themselves in a particular family or come from a specific heritage. Most tribes in Northern Ghana are patrilineal (inheritance from the father's blood line) and therefore consider relations from the paternal clan superior to those from the maternal line. In effect, "my father's son is better regarded by me than my mother's son with a different father. This is because while the former relates to me patrilineally, the latter is related matrilineally". This account for why it is easy for one to brand a person from the maternal side as a witch or a wizard but will never try that on a relation from the paternal blood line. This discrimination is sociologically not right and unacceptable.

\subsubsection{Personal Life}

It is possible for individuals to plot against others they consider a threat or rival(s), (say a competition or quarrel over the love of a woman) especially when their victims come from the maternal blood line or outside their yir. It might not be surprising that the fear of such opponents can influence a false accusation of penis theft which may be collaborated by conspirators to get innocent person(s) lynched. The African, especially the Ghanaian way of mob justice (injustice) is deadly since the victim might not only be beaten with clubs, stones and other implements but might be set ablaze with vehicle tyres and petrol. When this happens, it might be too late for the security agencies (who already are perceived to have a slow response time) to rescue the victim when the news gets to them.

\subsubsection{Societal Life}

The society might be suspicious of strangers or visitors who enter their community at a time when the beliefs of genital theft are rife. Some people may also distance themselves from others lest their genitals vanish or they are accused of committing genital theft. This affects associations at church, family meetings as well as the attendance of social programmes hence weakens the social bonding, solidarity and the 'we' feeling among members of a society.

\subsubsection{Economic Life}

The outward display of insecurity and fear; on a personal and collective levels have dire consequences on the economic life of the society. Teachers, doctors, bankers and other professionals posted to that area from other parts of the country may escape the bizarre circumstances of Genital Theft taking place there. Those who will remain in the town may not come out of their homes to engage in any venture. This can hinder greatly economic activities thereby stifling development.

\subsection{Conclusion}

The incidence at Zorse exposes the external insecurity and fear of the people in relation to their identity in diverse ways. The menace of genital theft started from Africa (some believe it originated from Nigeria) and perpetrated by Africans against their own people. This matter presents a test case to the viability of one's family background in the larger society. Without details like these, it will be difficult to draw appropriate conclusions. 


\section{Macrothink

The insecurity and fear posed to collective identity has a direct correlation with the threat of who a person is. This is because the identity of a person is a social construct.

The issue is not about losing the identity as people but the loss of power over an individual as well as collective identity. Genitals are the window to childbirth and their loss is tantamount to discontinuation of one's lineage. Dealing with genital theft matters through the court system or by mob attacks, reiterate autonomy of the society and its capacity for self - identification. In brief, the phenomenon of genital theft is a representation of the external insecurity and fear entertained by the society as result of delusional disorder.

\subsection{Evaluation and Recommendations}

This brief review has brought to the fore the phenomenon that witchcraft is acquired not within the yir but through maternal blood relation or outside of the patrilineal lineage which becomes evident in that particular community in Africa. Again, traditional beliefs and culture held on to by Africans are likely to account for people's genitals that vanish. It also became evident that black magic believed to be from Nigeria work perfectly on other Africans but not the Nigerians.

Genitals are the window to childbirth and their loss is tantamount to discontinuation of one's lineage as stated earlier. The reviewers recommend that as much as possible Africans must shun some localized and institutionalized belief systems such as the belief in the disappearance of genitals since they impact negatively on the community.

Finally, the perceived importation of magical powers (black magic) from Nigeria and other places in order to cast spells on Africans must stop and there must be institutionalized laws to deal with how individuals and groups hold firmly on to these belief systems and operationalized them in the African societies.

\section{Acknowledgment}

This paper is a summary of the original paper written by Charles Mather. We therefore owe all the content rights and the intellectual ideas in this write-up to Charles Mather and he is duly acknowledged as the original owner of the source document from which this review was written. We would like to also thank reviewers and editors for providing valuable suggestions to improve the reviewed paper.

\section{References}

Awedoba, A. K. (1989a). Notes on Matrimonial Goods Among the Atoende Kusasi, Part 1. Research Review, 5(1), 37-53.

Awedoba, A. K. (1989b). Matrimonial Goods among the Atoende Kusasi Contingent Prestations, Part 2. Research Review, 5(2), 1-17.

Awedoba, A. K. (1990). Matrimonial Goods Among the Atoende Kusasi: Matrimonial Prestations and Exploitation, Part 3. Research Review, 6(1), 49-56. 
Dan-Ali, M. (2001). "Missing” Penis Sparks Mob Lynching. Electronic document. Retrieved 7 May, 2002 from http://news.bbc. co.uk/l/hi/world/africa/127425.stm

Bartholomew, R. E. (1994). The Social Psychology of 'Epidemic' Koro. International Journal of Social Psychiatry, 40(1), 46-60 https://doi.org/10.1177\%2F002076409404000105

Bartholomew, R. E. (2000). Exotic Deviance. Boulder, CO: University of Colorado Press. https://doi.org/10.1177\%2F136346159803500101

Chowdhury, A. N. (1996). The Definition and Classification of Koro. Culture, Medicine and Psychiatry, 20(1), 41-65. https://doi.org/10.1007/BF00118750

Chowdhury, A. N., \& Bera, N. K. (1994). Koro Following Cannabis Smoking: Two Case Reports. Addiction, $\quad 89(8), \quad$ 1017-1020. https://doi.org/10.1111/j.13600443.1994.tb03361.x

Edwards, J. W. (1984). Indigenous Koro, a Genital Retraction Syndrome of Insular Southeast Asia: A Critical Review. Culture, Medicine and Psychiatry, 8, 1-24. https://doi.org/10.1007/BF00053099

Hallowell, A. (1941). The Social Function of Anxiety in a Primitive Society. American Sociological Review, 6(6), 869-881. https://doi.org/10.2307/2085768

\section{Copyright Disclaimer}

Copyright for this article is retained by the author(s), with first publication rights granted to the journal.

This is an open-access article distributed under the terms and conditions of the Creative Commons Attribution license (http://creativecommons.org/licenses/by/3.0/). 